\title{
DIGITAL PLANNING, CONSTRUCTION SUBMISSION AND APPROVAL PROCESSES IN AUSTRIA
}

DOI: 10.18485/arh_pt.2020.7.ch24

_ Kurt Battisti

A-NULL Development GmbH

\section{_ Markus Dörn}

A-NULL Development GmbH

\section{_ Christoph Eichler}

tbw solutions ZT GesmbH \& Flughafen Wien AG

\author{
_ Jacqueline Scherret \\ A-NULL Development $\mathrm{GmbH}$
}

\section{_ Torsten Ullrich}

Fraunhofer Austria Research GmbH \& Graz

University of Technology, torsten.ullrich@fraunhofer.at

\begin{abstract}
In Austria, standard A6241-2 created the normative basis for the exchange of model-based data in building construction and civil engineering in 2015. This technology - known internationally as Building Information Modelling (BIM) - is an essential building block for the digitization of the construction industry and has an impact on all those involved in the initiation, planning, construction and operation of buildings. This article describes the state-of-the-art in official approval processes in Austria. It examines the digital process path, i.e. the provision of cadastral data, the usability of provided GIS data, the existence of automated preliminary inspection, and accelerated processing by means of e-government. Representative examples are used to illustrate the current state of official approval processes in Austria.
\end{abstract}

The focus here is on the possibility of condensing the various public and semi-public basic planning data (location and environment) to prepare a consolidated requirements model, which can be used in BIM planning in the design and approval phase. It is shown where there are supplementary and overlapping data to identify conflict situations. In the future, a building applicant will be given the opportunity to complete the process online. This creates a clear time saving in relation to the processing time. This in turn accelerates the processing of projects and makes it easier for all parties involved.

KEYWORDS _ approval processes, digital planning, e-government, building information modeling (BIM), geographic information system (GIS) 


\section{INTRODUCTION}

In the current international as well as national development of BIM technology, there has been a significant change from so-called closedBIM to openBIM in the last few years. While closedBIM only allows data exchange between software products of one manufacturer or a selected product range, openBIM offers the potential to exchange data between software products of many different manufacturers due to a freely available, open, fully documented interface. The interface is subject to strict specifications - defined in Austria by ON A6241-2 - and thus guarantees (at least in theory) loss-free data exchange between all parties involved in the construction industry.

This development is particularly important for the development of BIM with regard to the legal framework conditions, with its requirements and warranty specifications under public procurement law, which do not allow a restriction of the possible software products in the planning and establishment of the planning team or the execution. openBIM guarantees above all small and medium-sized enterprises (SMEs) their access to all projects which would have been accessible only to large structures under closedBIM, and also allows the uncomplicated combination of several SMEs to form joint ventures for large projects. In general, the SME sector offers a more diverse range of software, which makes the use of a uniform data interface indispensable.

\section{TECHNOLOGICAL DEVELOPMENT}

According to Laakso and Kiviniemi (2012) advances in data exchange from the early days of Cpmputer-Aided Design (CAD) can be divided into three distinct generations of data exchange methods: During the first generation of exchange methods (1950-1970), closed and proprietary solutions were used exclusively, due to the limited needs; computers were mainly used to perform specific calculation tasks.

The second generation of exchange standards emerged in the late 1970s and endured to the mid 1980s. In this time open formats for the representation of basic geometry began to emerge, of which perhaps the most notable is IGES (Initial Graphics Exchange Specification), a neutral exchange standard for $C A D$ models. Open exchange standards were a new concept at the time and were initially considered a threatening proposition for CAD vendors.

The third generation of exchange formats started in 1984 when the TC184/SC4 subcommittee of ISO declared that none of the existing formats could on their own be extended to serve the needs of an open computer modeling standard for multiple industrial and manufacturing industries. That point marks the beginning of the development of STEP. In December 1994, the initial release of STEP became an international standard: ISO10303:1994, Industrial Automation Systems and Integration - Product data representation and exchange.

Using existing parts from the ISO STEP standard, most notably incorporating concepts from the Building Construction Core Model (BCCM) and the definitions for geometric representation, technical development did not begin from scratch: about half of the objects and types present in the first IFC releases were adopted from the integrated resources of STEP.

Nevertheless, the task of composing a complete data model is no small task. IFC was always intended to be a high-level data model, like STEP, which exists above software implementations to remain truly neutral and future-proof. It provides a standardized data structure for the storage of building information, but does not itself enforce, or even enable, any specific way of implementing it into software.

With development formally launched in September 1995, IFC 1.0 was published in January 1997. The release, having a very limited scope, focused primarily on the architectural part of the building model, incorporating five processes for architecture, two for HVAC design, two for construction management, and one for facilities management. The scope of IFC 2.0 was primarily to incorporate schemas for building services, cost estimation, and construction planning; the final release was delivered in April 1999. Afterwards, the standardization focus shifted from to enable software in- 
teroperability in the AEC/FM industry to Improving communication, productivity, delivery time, cost, and quality throughout the whole building life cycle. Consequently, the following versions introduced among others the IFC Model View Definition Format (MVD) and the concept of the useful minimum: "The minimum scope for data exchange, which makes IFC based exchange a better solution than any other available format." As illustrated in Figure 1, the current version is IFC 4. More details on the history of IFC can be found in the article "The IFC Standard - A Review of History, Development, and Standardization" by Mikael Laakso and Arto Kiviniemi (2012).

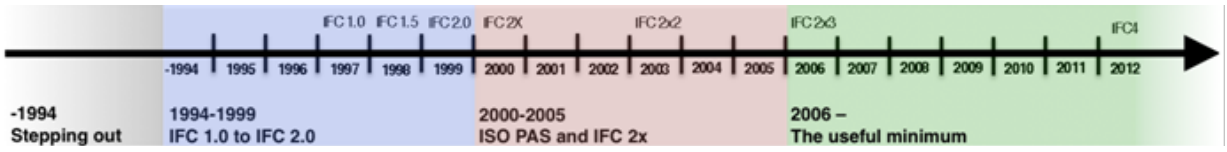

_ Figure 1: The IFC timeline. (image source: "The IFC Standard - A Review of History, Development, and Standardization" by Laakso and Kiviniemi, 2012)

\section{POLITICAL DEVELOPMENT}

Because of its focus on ease of interoperability between software platforms, On January 17th 2008, AEC/FM sector government client organizations from the US, Denmark, Finland, Norway, and the Netherlands issued a commonly signed "Statement of Intention to Support Building Information Modeling with Open Standards" on January 17th 2008 making the commitment to facilitate the use of the IFC standard very explicit.

This starting signal was used to address the problems caused by legal, social and technical barriers. Due to the different legal frameworks in different countries, the comparison at international level is relatively difficult. Paulsson and Paasch (2013) have published a comparison on "3D property research from a legal perspective" for the English-speaking world. With digitization, the processes that have arisen due to the requirements of analog conditions are usually also adapted (Ponnewitz, 2017; Choi and Kim, 2017). In addition to the "classic" advantages of a 3D cadastre, which result from automation, new business areas are also opening up, which drive the digital transformation (Isikdag et al., 2014; Köhler and Schnitzer, 2014). These digital transformations involve the interaction of many institutions and bodies and are not always supported by all of them. In the state-of-the-art article "Legal barriers to 3D cadaster implementation: What is the issue?" the authors (Ho et al., 2013) phrase it as follows:

"In conclusion, it is highly likely that the main barrier to cadastral innovation lies not in technological or legal issues, but more fundamental social and cultural issues that make up the institutional framework underpinning cadastral systems and its inherent processes."

\section{SITUATION IN EUROPE AND WORLD-WIDE}

From a technological point of view, merging Building Information Modeling (BIM) and Geographic Information System (GIS) data bases and consolidating data is often the first step. Since BIM and GIS were originally developed for different purposes, numerous challenges are being encountered for the integration. (Liu et al., 2017) present a state-of-the-art overview on the technological challenges enriched by a wide range of applications via integration of BIM and GIS and its potential. The main problems are usually semantic differences and the inability to represent the facts of one system in the other system (El-Mekawy and Östman, 2012). It is important that the mapping is unambiguous. The possibility of being able to map something somehow does more harm than good in data exchange if the data recipient has too much room for interpretation. In this context, the following problems are noteworthy:

There is currently no capacity in BIM for recording and representing information about ownership 
and boundaries of properties, which is core land administration information (Atazadeh et al., 2017). The extension of the IFC concepts of virtual spaces and zones could be a future way for virtual cadastral legal spaces to be defined within BIMs (Boyes et al., 2015; Oldfield et al., 2016).

Differences in geometry representations in GIS and BIM include the use of a global coordinate reference system (Onstein and Tognoni, 2017). One main principle in all GIS data, is refer to the earth. Horizontal and vertical positions need separate global coordinate reference systems (CRS), with different mappings from CRS-distances to real-world distances. Due to the earths shape and the wish to have homogeneous CRSs over as wide area as possible, all horizontal global CRSs imply a distortion. This distortion must be taken into account when calculating real world distances and directions from representations. In BIM data it is essential to have positions that give real world distances in all three dimensions direct from Euclidean coordinate calculations. IFC4 still misses the complete support of horizontal and vertical CRS.

Another difference between GIS and BIM is the access to data: Data is accessed with different objectives and subsequent requirements. (Atazadeh et al., 2019) conclude in their article on "Querying 3D Cadastral Information from BIM Models":

"The rich data environment of BIM could capture complex relationships between legal boundaries, ownership arrangements and their counterpart physical elements. However, effective management of $3 D$ cadastral information in a BIM environment is predicated on good data query mechanisms to deliver untapped knowledge about ownership arrangements and legal boundaries in spatially complex situations."

Furthermore, due to the longer periods of cadastral systems in comparison to BIM life cycles, earth changes, from plate tectonics, erosion, human intervention, etc. have to be taken into account (Navratil and Unger, 2013).

Due to the diverse challenges that can be addressed in different ways, the picture of the digital transformation varies from country to country. Most countries adopt a bottom-up strategy that starts in individual model regions or with individual use-cases:

Australia Several case studies in Australia are currently being carried out to identify the key issues of future requirements (Atazadeh et al., 2017; Atazadeh et al., 2019; Kitsakis et al., 2019).

China In China too, the requirements for a future BIM/GIS system are collected in "bottom-up" use-cases (Kaiwen and Minhua, 2009; Guo et al., 2011; Guo et al., 2013).

Egypt The building and construction industry in Egypt is mainly paper-based. First tests evaluate the legislative environment to introduce BIM-based code checking using bounding volumes (Nour, 2016).

Malaysia A research project in Malaysia takes up the special challenge of island groups and develops a GIS system for marine parcels (Abdul Rahman et al., 2012).

Singapore Singapore has always been a pioneer in the areas of BIM and e-government since 1995 (see www.corenet.gov.sg; Kaneta et al., 2016).

In Europe, a role comparable to Singapore is that of Norway (Onstein and Tognoni, 2017).

Norway Singapore and Norway rely on incentives and goodwill (Hjelseth, 2015):

"[...] has identified that it is the balance between the three perspectives; Integrated process, Collaborating people and Interoperable technology, which have contributed to the success of these two solutions. Lessons learned are that increased understanding of the balance between these perspectives is the much more important criteria for success, than initiatives to copy the "best" solution, or component for another country."

In technological terms, many contributions come from the Netherlands (Stoter et al, 2012; Van Berlo et al., 2013; Stoter et al., 2013) and Sweden (El-Mekawy et al., 2014). Other European projects are ongoing amongst others in:

France (Pouliot et al., 2013), Germany (Gruber et al., 2014),

Poland (Siejka et al., 2014), Slovenia (Drobež et al., 2017)

Spain (Valls Dalmau et al., 2014).

In addition to these national initiatives, the Czech government initiative is noteworthy in terms of legal certainty, accessibility and accuracy (Janecka and Soucek, 2017): 
"[...] the Strategy for the Development of the Infrastructure for Spatial Information in the Czech Republic to 2020 was recently approved. This represents a government initiative that emphasizes the creation of a National Set of Spatial Objects, which is defined as the source of both guaranteed and reference $3 D$ geographic data at the highest possible level of detail for selected objects covering the entire territory of the Czech Republic."

\section{SITUATION IN AUSTRIA}

Digitisation of the cadastral data is an essential prerequisite for being able to carry out approval processes completely digitally on the basis of BIM. The digital transformation of cadastral data currently includes the scanning of analogue paper plans and their conversion into PDF - a process which is expected to continue until 2024 (Hoffmann et al., 2017).

Parallel to this development, GIS systems are being set up at the federal level:

$\begin{array}{llll}\text { Burgenland } & \text { https://gis.bgld.gv.at } & \text { Carinthia https://kagis.ktn.gv.at } \\ \text { Lower Austria } & \text { https://atlas.noe.gv.at } & \text { Salzburg https://www.salzburg.gv.at } \\ \text { Styria } & \text { https://gis.stmk.gv.at } & \text { Tirol https://www.tirol.gv.at } \\ \text { Upper Austria } & \text { https://www.doris.at } & \text { Vienna } & \text { https://www.wien.gv.at }\end{array}$

Vorarlberg http://vogis.cnv.at

The pioneer of digitization in Austria has been Vienna. Numerous geodata are already available in Vienna. Therefore, the implementation of a 3D cadaster in connection with the GIS system would be a possibility to link all geodata. The existing data base in Vienna comprehends (without legal warranties):

- about 200.000 buildings with more than 650.000 structures;

- roof models especially for shadow simulation and visibility analysis;

- area-multipurpose-cards and multipurpose-cards;

- terrain model to digital represent the height of Vienna;

- a surface modell of airborne laser scans including orthophotos.

But the other federal states are also continuing to digitize. The cadastral plans can already be viewed online in each of the nine federal states and they can at least be downloaded as PDF.

\section{DIGITAL BUILDING SUBMISSION FOR THE CITY OF VIENNA}

The City of Vienna hosts a virtual municipal office on its website: www.wien.gv.at. Among other things, a digital building submission is offered there. The focus is on the systematic processing of legal obligations. In a guided process, the various data and documents necessary for the implementation of the procedure are collected. This service provides a clear overview of the different official requirements for specific projects.

The file formats PDF, JPEG or PNG are available/supported for the following topics

- General plans (overviews)

- Structural analysis with expertise

- Consent of the landowners

- Site plans

- Floor plans

- Views

- Sections

Other documents may also be sent, as required. Additional documents are:

- Proof of the building site

- Various authorizations

- Neighbors' agreement

- Necessary confirmations from civil engineers

- Descriptions of the technical installations

- Confirmations of accompanying requirements (energy efficiency, etc.)

Due to the current legal requirements, it is still necessary to transmit the data in a paper-based drawings and written form. Overall, this is an important first step in digitization. Through the in- 
teraction of the digital procedure with other administrative databases (address register, company register, ...), errors in assembling a closed data set for the building application can be minimized. The City of Vienna has taken an important first step with the online submission of building applications. In 2020, the research projects "BRISE - Building Regulations Information for Submission Envolvement" and "AMAzE - Automatische Einteichung" were launched. A broad project consortium with participants from science and research, as well as users from the construction industry, will increase efficiency of the processes in the near future.

\section{CONCLUSION}

The literature research indicates that the holistic view on 3D data faces major hurdles due to the different, historical developments of geographic data and building models. In personal conversations with Austrian stakeholders, we received confirmations that the technical challenge is not the biggest problem, but rather the mixed situation of different involved institutions, with different legal frameworks and political interests at municipal, state or national level. As a consequence, future research projects should not focus on technical problems, but rather address new, political ways to achieve a cooperation of all stakeholders towards a consistent, publicly available, geographic and building information system.

\section{REFERENCES}

- Abdul Rahman, Alias, van Oosterom, Peter, Chee Hua, Teng, Sharkawi, Khairul Hafiz, Duncan, Edward Eric, Azri, Norsuhaibah, and Hassan, Muhammad Imzan. 2012. "3D Modelling for Multipurpose Cadastre." International Workshop on 3D Cadastres (October) 3: 185-199.

- Atazadeh, Behnam, Kalantari, Mohsen, Rajabifard, Abbas, Ho, Serene, and Ngo, Tuan. 2017. "Building Information Modelling for High-rise Land Administration." Transactions in GIS 21: 91-113.

- Atazadeh, Behnam, Rajabifard, Abbas, Zhang, Yibo, and Barzegar, Maryam. 2019. "Querying 3D Cadastral Information from BIM Models." International Journal of Geo-Information 8 (July): 329.1-329.18.

- Boyes, Gareth, Thomson, Charles, and Ellul, Claire. 2015. "Integrating BIM and GIS: Exploring the use of IFC space objects and boundaries." Proceedings of GIS Research UK (GISRUK) 23 (April): 98-106.

- Choi, Jungsik, and Kim, Inhan. 2017. "A Methodology of Building Code Checking System for Building Permission based on openBIM." International Symposium on Automation and Robotics in Construction 34 (July): 945-950.

- Drobež, Petra, Fras, Mojca Kosmatin, Ferlan, Miran, and Lisec, Anka. 2017. "Transition from 2D to 3D real property cadastre: The case of the Slovenian cadaster." Computers, Environment and Urban Systems 62: 125-135.

_ El-Mekawy, Mohamed, and Östman, Anders. 2012. "Feasibility of Building Information Models for 3D Cadastre in Unified City Models." International Journal of E-Planning Research 1 (October): 35-58.

- El-Mekawy, Mohamed, Paasch, Jesper, and Paulsson, Jenny. 2014. "Integration of 3D Cadastre, 3D Property Formation and BIM in Sweden". International Workshop on 3D Cadastres 4 (November): 17-34. - Gruber, Ulrike, Riecken, Jens, and Seifert, Markus. 2014. "Germany on the Way to 3D-Cadastre." Zeitschrift für Geodäsie, Geoinformation und Landmanagement 139: 223-228.

_ Guo, Renzhong, Li, Lin, He, Biao, Ying, Shen, Zhao, Zhigang, and Jiang, Renrong. 2011. "3D Cadastre in China - a Case Study in Shenzhen City." International Workshop on 3D Cadastres 2 (November): 291-306. _ Guo, Renzhong, Li, Lin, Ying, Shen, Luo, Ping, He, Biao, and Jiang, Renrong. 2013. "Developing a 3D cadastre for the administration of urban land use: A case study of Shenzhen, China." Computers, Environment and Urban Systems 40 (August): 46-55.

- Hjelseth, E. 2015. „Public BIM-based model checking solutions - Lessons learned from Singapore and Norway." Transactions on The Built Environment 149 (Sept.): 421-436. 
_ Ho, Serene, Rajabifard, Abbas, Stoter, Jantien, and Kalantari, Mohsen. 2017. "Legal barriers to 3D cadastre implementation: What is the issue?." Land Use Policy 35 (June): 379-387.

_ Hoffmann, Wernher, Klotz, Stefan, Krieglsteiner, Ronald, and Topf, Georg. 2017. "Aktuelle Situation des Katasters in Österreich aus der Sicht der Datenverarbeitung." In 200 Jahre Kataster: Öster-reichisches Kulturgut 1817-2017, edited by Bundesamt für Eich- und Vermessungswesen, 173-187. Wien: Bundesamt für Eich- und Vermessungswesen.

- Isikdag, Umit, Horhammer, M., Zlatanova, Sisi, Kathmann, R., van Oosterom, P. 2014. "Semantically rich 3D building and cadastral models for valuation." International Workshop on 3D Cadastres 4 (November): 35-54.

- Janecka, Karel, and Soucek, Petr. 2017. "A Country Profile of the Czech Republic Based on an LADM for the Development of a 3D Cadastre." International Journal of Geo-Information 6 (May): 143.1-142.19.

_ Kaiwen, Tang, and Minhua, Yang. 2009. "Registration for 3d Cadastre in China." International Forum on Computer Science-Technology and Applications: 79-82.

- Kaneta, Takashi, Furusaka, Shuzo, Tamura, Atsushi, and Deng, Nisi. 2016. "Overview of BIM Implementation in Singapore and Japan." Journal of Civil Engineering and Architecture 10: 1305-1312.

- Kitsakis, Dimitrios, Kalantari, Mohsen, Rajabifard, Abbas, Atazadeh, Behnam, and Dimopoulou, Efi. 2019. "Exploring the 3rd dimension within public law restrictions: a case study of Victoria, Australia." Land Use Policy 85 (April): 195-206.

_ Köhler, Tine, Schnitzer, Benjamin. 2014. "Urban Mining Cadastre - a Geospatial Data Challenge." Fédération International des Géomètres (FIG) Congress 25 (June): 1-18.

- Laakso, Mikael, and Kiviniemi, Arto. 2012. "The IFC Standard - A Review of History, Development, and Standardization." Journal of Information Technology in Construction 17 (May): 134-161.

- Liu, Xin, Wang, Xiangyu, Wright, Graeme, Cheng, Jack C. P., Li, Xiao, and Liu, Rui. 2017. "A State-of-the-Art Review on the Integration of Building Information Modeling (BIM) and Geographic Information System (GIS)." International Journal of Geo-Information 53 (February): 6.1-6.22.

- Navratil, Gerhard, and Unger, Eva-Maria. 2013. "Requirements of 3D cadastres for height systems." Computers, Environment und Urban Systems 40: 14-23.

_ Nour, Mohamed Magdy Abdelaziz. 2016. "Using Bounding Volumes for BIM based electronic code checking for Buildings in Egypt." Journal of Engineering Research 5: 91-98.

_ Oldfield, Jennifer, van Oosterom, Peter, Quak, Wilko, van der Veen, Jeroen, and Beetz, Jakob. 2016. "Can Data from BIMs be Used as Input for a 3D Cadastre?" International Workshop on 3D Cadastres 5 (October): 199-214.

_ Olsson, Per-Ola, Axelsson, Josefine, Hooper, Martin, and Harrie, Lars. 2018. "Automation of Building Permission by Integration of BIM and Geospatial Data." International Journal of Geo-Information 7 (July): 307.1-307.22.

_ Onstein, Erliong, and Tognoni, Matias Gonzalez. 2017. "'Building Permits' as Proof of Concepts in Merging GIS and BIM Information: a Case Study." Transactions on The Built Environment 169: 155-166.

_ Paulsson, Jenny, and Paasch, Jesper M. 2013. "3D Property Research from a Legal Perspective." Computers, Environment and Urban Systems 40: 7-13.

_ Ponnewitz, Judith. 2017. "BIM-based Building Permit Procedures using Decision Making Methods." Proceedings of the Winter Simulation Conference 50: 4652-4653.

_ Pouliot, Jacynthe Vasseur, Marc, and Boubehrezh, Abbas. 2013. "How the ISO 19152 Land Administration Domain Model performs in the comparison of cadastral systems: A case study of condominium/ co-ownership in Quebec (Canada) and Alsace Moselle (France)." Computers, Environment and Urban Systems 20: 68-78.

_ Siejka, M., Ślusarski, M., and Zygmunt, M. 2014. "3D+time Cadastre, possibility of implementation in Poland." Survey Review 46: 79-89.

- Stoter, Jantien, van Oosterom, Peter, and Ploeger, Hendrik. 2012. "The Phased 3D Cadastre Implementation in the Netherlands." International Workshop on 3D Cadastres 3 (October): 203-218.

- Stoter, Jantien, Ploeger, Hendrik, and van Oosterom, Peter. 2013. "3D cadastre in the Netherlands: Developments and international applicability." Computers, Environment and Urban Systems 40: 56-67.

- Valls Dalmau, Francesc, Garcia-Almirall, Pilar, Redondo Domínguez, Ernest, and Fonseca Escudero, David. 2014. "From Raw Data to Meaningful Information: A Representational Approach to Cadastral Databases in Relation to Urban Planning." Future Internet 6: 612-639.

_ Van Berlo, L., Dijkmans, T. and Stoter, J. 2013. "Experiment for Integrating Dutch 3D Spatial Planning and BIM for Checking Building Permits." Annals of the Photogrammetry, Remote Sensing and Spatial Information Sciences 8 (November): 279-284. 